\title{
Preface
}

This is the third collection of my essays for general readers published by Harvard University Press. Some of these essays are polemics on subjects such the harm done by inequality, the folly of programs of manned space flight, the wrongheadedness of some fashions in writing history, the danger of global warming, and the importance of support for public goods, including basic science. As before, they present a point of view that is rationalist, realist, reductionist, and devoutly secular.

Other essays aim at explaining aspects of modern physics and cosmology and their past in nontechnical terms. In some cases footnotes have been added to clarify things that may have been obscure in the essays as originally published. I fear that the reader will find some scientific topics repeated from one essay to another, including broken symmetry, weak and strong nuclear forces, the early universe, and the multiverse. It can't be helped-these days, these topics are much on the minds of many physicists.

As in the earlier collections, Facing Up and Lake Views, most of these essays were published in the New York Review of Books, in newspapers, and in other periodicals. Essays 20, 23, and 25 are brief talks given at university graduations, and have not been previously published. Essay 24 has not been published until now because everyone who read it disagreed with it, but I am fond of it and so bring it out here.

In this volume I have departed from my practice in earlier essay collections, in which I arranged all essays together in 
chronological order. I have here instead sorted the essays out into four broad categories, and arranged them in chronological order only within each category. But these categories should not be taken too seriously. In discussing historical matters in Part I, I have had to explain aspects of physics and astronomy, and I have not been able to discuss physics and astronomy in Part II without giving some account of their history. Both science and its history also intrude here and there in Parts III and IV, on public and personal matters.

I owe a great debt to editors who have helped to bring these essays to the reading public. In particular, thanks are due to Michael Fisher, who first suggested that Harvard University Press bring out a collection of my essays, to Jeff Dean, for good advice and for seeing the current collection through to publication, and to the late Robert Silvers, who worked with unending skill and patience to improve my articles in the New York Review of Books. I take this opportunity to give special thanks to Louise Weinberg. Taking time from her own writings on law, she read the early drafts of many of these articles, provided the titles for many of them and for Facing Up and To Explain the World, suggested the Grimshaw painting for the jacket of this volume, and gave valuable advice about rearranging material. Many obscurities and puerilities were avoided through her help.

From past experience, it seems that at my rate of writing it takes about a decade to produce enough new essays for assembly in a collection. I hope nevertheless that this will not be my last collection. But given actuarial realities, perhaps this would be a good time for me to add a word of thanks to readers who over many years have put up with my polemics and explanations, and have thereby given me a precious contact with the world beyond physics. 


\section{THIRD THOUGHTS}


